\title{
Human Toxoplasma gondii-specific Secretory Immunoglobulin A Reduces $T$. gondii Infection of Enterocytes In Vitro
}

\author{
D. G. Mack * and R. McLeod *\$\$ \\ * Departments of Medicine, Immunology, and Microbiology, Michael Reese Hospital and Medical Center, Chicago, Illinois 60616; \\ ${ }^{\ddagger}$ The University of Illinois at Chicago; and ${ }^{\S}$ The University of Chicago Pritzker School of Medicine, Chicago, Illinois 60637
}

\begin{abstract}
Whey from 17 women (four acutely infected with Toxoplasma gondii, eight chronically infected, and five uninfected ) was studied. $T$. gondii-specific secretory IgA antibodies were demonstrated by ELISA in whey from acutely infected and one of eight chronically infected women. Such antibodies to tachyzoite proteins of $\leq 14,22,26-28,30,46,60,70-80$, and $>100 \mathrm{kD}$ (eliminated by protease but not periodate or neuraminidase treatment) were demonstrated in whey from acutely infected subjects when Western blots were probed with their whey and antibodies to human secretory $\operatorname{IgA}$ or $\operatorname{IgA}$ or secretory piece. Secretory IgA from four of eight chronically infected women recognized the 46- and $69-\mathrm{kD}$ epitopes. Other whey samples were negative. Incubation of $T$. gondii tachyzoites with whey or purified secretory IgA from acutely infected (but not seronegative) women caused $50-75 \%$ reduction in infection of enterocytes in vitro. Whey reactive with the 46-kD epitope from three of six chronically infected women caused less $(\geq 40 \%)$ inhibition. Whey and purified secretory IgA from two of three acutely infected women agglutinated tachyzoites. Whey did not result in complement-dependent lysis of $\boldsymbol{T}$. gondii. These results indicate that it may be possible to produce human secretory IgA to $T$. gondii capable of reducing initial infection of enterocytes, as such IgA is present during natural infection. They also demonstrate candidate epitopes for such protection. (J. Clin. Invest. 1992.90:2585-2592.) Key words: Toxoplasma gondii infection - whey • secretory antibody • epitopes • agglutination • fab
\end{abstract}

\section{Introduction}

Toxoplasma gondii can cause death, systemic illness, and loss of sight, hearing, cognitive, or other neurological function when it is acquired congenitally or in immunocompromised individuals $(1,2)$. One strategy for development of protective preparations against organisms that initially infect via the intestine has been to stimulate intestinal, organism-specific secretory IgA (3-19). As T. gondii is initially acquired perorally (1), we studied whether humans produced such $T$. gondii-specific secretory IgA. Milk was used as the source of the secretory IgA. Epitopes recognized by such IgA then were characterized and

Address correspondence and reprint requests to Rima McLeod, M.D., Department of Medicine, Michael Reese Hospital and Medical Center, Lake Shore Drive at 31st Street, Chicago, IL 60616.

Received for publication 7 August 1990 and in revised form 30 June 1992

J. Clin. Invest.

(C) The American Society for Clinical Investigation, Inc.

$0021-9738 / 92 / 12 / 2585 / 08 \$ 2.00$

Volume 90, December 1992, 2585-2592 the effect of this secretory IgA on infection of enterocytes in vitro was determined.

\section{Methods}

Collection of milk samples. Milk samples were obtained from 17 women. Serologic tests were performed by Dr. Jack Remington's laboratory (Stanford University and Palo Alto Medical Research Institute, Palo Alto, CA) as described $(1,2)$. Serologic test results for these women are in Table I. Five were uninfected (i.e., $T$. gondii seronegative in the Sabin Feldman Dye test [negative]); seven were chronically infected (i.e., $T$. gondii IgG seropositive, but IgM seronegative in the double sandwich IgM ELISA [chronic]); one had been infected periconceptually although serologic tests retained an acute pattern at the time her milk was obtained (subacute); and four were acutely infected (i.e., $T$. gondii IgM seropositive and AC/HS (a differential agglutination test) acute and three of these were mothers of a congenitally infected infants [acute]). Milk samples were obtained according to $\mathrm{Na}$ tional Institutes of Health guidelines concerning human subjects. Milk samples were collected by the women through manual expression and were immediately frozen at $-20^{\circ} \mathrm{C}$. Before analyses, samples were centrifuged at $10,000 \mathrm{~g}$ for $1 \mathrm{~h}$ to remove lipids. The clear middle layer was collected. Samples were divided into separate aliquots and stored at $-135^{\circ} \mathrm{C}$ until analyzed. The studies described herein were performed within 1 yr of collection of the milk samples.

Preparation of $T$. gondii antigen for ELISA. Swiss Webster (SW) female mice (Harlan Sprague Dawley, Inc., Indianapolis, IN) that weighed $18-20 \mathrm{~g}$ were used. $2 \times 10^{7} \mathrm{RH}$ strain tachyzoites in $0.2 \mathrm{ml}$ isotonic saline were injected intraperitoneally into Swiss Webster mice. $2 \mathrm{~d}$ later, $5 \mathrm{ml}$ of isotonic PBS, pH 7.4, was injected into the peritoneal cavity and the ascites-PBS suspension containing the parasite was aspirated. This suspension was forced through a 27 -gauge needle to disrupt infected peritoneal exudate cells and filtered through a funnel lined with glass wool. It was then passed through a polycarbonate membrane filter with a $3-\mu \mathrm{m}$ pore diameter (Nuclepore Corp., Pleasanton, CA) to remove host cells. The filtered parasites were washed three times in PBS and centrifuged at $400 \mathrm{~g}$ for $15 \mathrm{~min}$ at $4^{\circ} \mathrm{C}$ and were resuspended in distilled water at a concentration of $5 \times 10^{8} / \mathrm{ml}$; they were then sonicated three times for $30 \mathrm{~s}$ each time, and centrifuged at $10,000 \mathrm{~g}$ for 15 $\min$ at $4^{\circ} \mathrm{C}$ to remove cellular debris. The concentration of the soluble $T$. gondii lysate antigen was determined by the Lowry method (20).

$T$. gondii-specific sIgA ELISA. Wells of polystyrene microtiter plates (Dynatech Laboratories, Inc., Chantilly, VA) were coated with $100 \mu \mathrm{l} \mathrm{T}$. gondii lysate antigen $(50 \mu \mathrm{g} / \mathrm{ml})$ in $0.1 \mathrm{M}$ carbonate buffer, $\mathrm{pH}$ 9.6. After an overnight incubation at $4^{\circ} \mathrm{C}$, the plates were washed three times with $0.1 \mathrm{M}$ PBS containing $0.5 \%$ Tween 20 (Sigma Chemical Co., St. Louis, MO), pH 7.2 (PBS-T), and postcoated with 4\% bovine serum albumin, fraction V (Calbiochem Corp., La Jolla, CA ) in PBS (PBS-B) for $1 \mathrm{~h}$ at $37^{\circ} \mathrm{C} .100 \mu \mathrm{l}$ of twofold serial dilutions of the whey samples in PBS-TB was added to each well. The plates were incubated for $1 \mathrm{~h}$ at $37^{\circ} \mathrm{C}$ followed by three washes in PBS-T. $100 \mu \mathrm{l}$ of alkaline phosphatase-conjugated goat anti-human secretory IgA (Cappel Laboratories, West Chester, PA) diluted in PBS-TB was added to each well. The plates were incubated for $1 \mathrm{~h}$ at $37^{\circ} \mathrm{C}$ followed by three washes in PBS-T. $100 \mu \mathrm{l}$ of nitrophenyl phosphate $(1 \mathrm{mg} / \mathrm{ml}$; Sigma Chemical Co.) diluted in $0.05 \mathrm{M}$ carbonate buffer, $\mathrm{pH}$ 9.6, was added to each well followed by an incubation for $1 \mathrm{~h}$ at $37^{\circ} \mathrm{C}$, and the 
Table I. Serologic Test Results for Women from Whom Whey was Obtained

\begin{tabular}{lrrlrrrrrr}
\hline $\begin{array}{c}\text { Status of } \\
\text { infection }\end{array}$ & $\begin{array}{c}\text { Subject } \\
\text { number }\end{array}$ & $\begin{array}{c}\text { Infant } \\
\text { DOB }\end{array}$ & $\begin{array}{c}\text { Estimate of } \\
\text { trimester of } \\
\text { acquisition }\end{array}$ & $\begin{array}{c}\text { Data sera } \\
\text { obtained }\end{array}$ & $\begin{array}{c}\text { Date milk } \\
\text { obtained }\end{array}$ & $\begin{array}{c}\text { Reciprocal } \\
\text { of serum } \\
\text { dye test* }\end{array}$ & $\begin{array}{c}\text { Serum } \\
\text { IgM ELISA* }\end{array}$ & $\begin{array}{c}\text { Serum } \\
\text { IgA ELISA* }\end{array}$ & $\begin{array}{c}\text { Serum } \\
\text { AC/HS* }\end{array}$ \\
\hline Acute & 1 & $11 / 90$ & Second & $9 / 90$ & $11 / 90$ & 8,000 & 7.7 & 9.4 & $>1,600 / 1,600$ \\
Acute & 2 & $10 / 90$ & Third & $11 / 90$ & $11 / 90$ & 1,024 & 3.9 & 5.6 & $>1,600 / 3,200$ \\
Acute & 3 & $3 / 89$ & Third & $7 / 89$ & $5 / 89$ & 4,096 & 4.8 & ND & $>1,600 / 3,200$ \\
Acute & 17 & $1 / 91$ & Third & $4 / 91$ & $4 / 91$ & 8,000 & 10.8 & ND & $>1,600 / 3,200$ \\
Subacute & $4^{\ddagger}$ & $8 / 90$ & Periconceptual & $11 / 90$ & $11 / 90$ & 256 & 3.0 & 5.6 & $400 / 800$ \\
Chronic & 5 & $7 / 89$ & Not applicable & $9 / 89$ & $9 / 89$ & 512 & 0.2 & ND \\
Chronic & 6 & $9 / 90$ & Not applicable & $11 / 90$ & $11 / 90$ & Positive & Negative & ND & ND \\
Chronic & 7 & $1 / 91$ & Not applicable & $2 / 91$ & $1 / 91$ & 512 & 0.5 & ND \\
Chronic & 8 & $1 / 91$ & Not applicable & $1 / 89$ & $2 / 91$ & 1,024 & 1.6 & ND & $50 / 3,200$ \\
Chronic & 9 & $12 / 90$ & Not applicable & $6 / 87$ & $1 / 91$ & 16,000 & 1.6 & ND \\
Chronic & 10 & $11 / 90$ & Not applicable & $12 / 90$ & $12 / 90$ & 64 & 0.1 & ND \\
Chronic & 11 & $10 / 90$ & Not applicable & $10 / 90$ & $11 / 90$ & 32 & 0.4 & ND \\
Uninfected & 12 & $7 / 90$ & Not applicable & $10 / 90$ & $11 / 90$ & Negative & ND & ND \\
Uninfected & 13 & $9 / 90$ & Not applicable & $11 / 90$ & $1 / 91$ & Negative & ND & ND & ND \\
Uninfected & 14 & $3 / 90$ & Not applicable & $1 / 90$ & $10 / 90$ & Negative & ND & ND \\
Uninfected & 15 & $12 / 89$ & Not applicable & $10 / 90$ & $10 / 90$ & Negative & ND & ND & ND \\
Uninfected & 16 & $3 / 89$ & Not applicable & $9 / 89$ & $9 / 89$ & Negative & ND & ND \\
\hline
\end{tabular}

* At the time milk sample was obtained; AC/HS refers to the "Differential agglutination" test of Desmonts, Thulliez, and Remington. This test uses acetone (AC)- and formalin (HS)-fixed tachyzoites. It is useful in determining whether infection was acquired in the 6 mo before the time when the serum sample was obtained. The results for the acutely and subacutely infected women demonstrate that their infections were recently acquired. ${ }^{\ddagger}$ Treated with spiramycin during gestation. ${ }^{\S} \mathrm{IgG}$ by EIA, IgM by IFA.

absorbance was determined at $405 \mathrm{~nm}$ using an ELISA reader. Specific antibody titer was determined as the last dilution that yielded an absorbance two times that of the negative control.

Total sIgA ELISA. The quantification of total IgA in whey using an ELISA was performed as described under $T$. gondii-specific $\operatorname{sIgA}$ ELISA with modifications. Briefly, microtiter plates were coated with $100 \mu \mathrm{l}$ anti-human secretory component $(1 \mu \mathrm{g} / \mathrm{ml}$; Sigma Chemical Co.) rather than $T$. gondii lysate antigen and fivefold serial dilutions of milk samples were used. Standard curves were constructed using known amounts of $\operatorname{IgA}(0.145-710 \mu \mathrm{g} / \mathrm{ml})$. Correlations between $\log _{10}$ OD readings and $\log _{10}$ concentration of $\mathrm{IgA}$ were linear in this range and highly significant $(R=0.97)$.

Isolation of $\operatorname{IgA}$. Milk samples were diluted 1:1 with PBS and applied to a $5.0 \mathrm{ml}$ column of immobilized jacalin crosslinked to $6 \%$ beaded agarose (Pierce Chemical Co., Rockford, IL) (21). The column was washed with $25 \mathrm{ml}$ of PBS. The IgA was eluted with PBS containing 0.1 M melibiose (Sigma Chemical Co.) and 1-ml were fractions collected. The peak fractions were pooled and the buffer was exchanged with PBS using a microconcentration system, molecular weight cutoff, 30,000 (Centricon 30; Amicon Corp., Danvers, MA). The concentrate was filtered using a $0.45-\mu \mathrm{m}$ filter (Gelman Sciences Inc., Ann Arbor, $\mathrm{MI})$ and then stored at $-135^{\circ} \mathrm{C}$.

Maintenance of enterocytes. Enterocytes (ATCC CRL 1592, IEC-6 [22]) were grown in $75-\mathrm{cm}^{2}$ flasks containing Dulbecco's minimal essential medium (DMEM) ${ }^{1}$ (Gibco Laboratories, Grand Island, NY), $10 \% \mathrm{FCS}$ (which had been heated for $1 \mathrm{~h}$ at $56^{\circ} \mathrm{C}$ to inactivate complement) (HyClone Laboratories Inc., Logan, UT), containing $1.0 \%$ glutamine, $100 \mathrm{U} / \mathrm{ml}$ penicillin, $100 \mu \mathrm{g} / \mathrm{ml}$ streptomycin, and $2.5 \mu \mathrm{g} / \mathrm{ml}$ amphotericin B (DMEM, 10\% FCS). They were split 1:5 for propagation or harvested for a challenge when they were confluent ( $\sim 3-4 \mathrm{~d}$ after initiation of cultures).

Preparation of Me49 tachyzoites for in vitro challenge. Me49 tachyzoites were propagated in an L929 macrophage cell line (kindly pro-

1. Abbreviation used in this paper: DMEM, Dulbecco's minimal essential medium. vided by Dr. Frank Fitch, The University of Chicago, Chicago, IL) in 75- $\mathrm{cm}^{2}$ flasks (Nunc, Roskilde, Denmark) containing DMEM, $10 \%$ FCS. L929 cells were split 1:10 $\left(10^{6}\right)$ every $3-4$ d. Free tachyzoites along with tachyzoite-infected cells from a 3-4-d infected monolayer were split $1: 10$ and $10^{7}$ were added to $10^{6}$ uninfected L929 cells to propagate the tachyzoites.

To prepare tachyzoites for in vitro challenge, infected monolayers were scraped with a rubber policeman to dislodge free tachyzoites and infected cells. The suspension was passed through a 27-gauge needle and a funnel lined with glass wool and was filtered free of host cells as described (23). The tachyzoites were centrifuged at $400 \mathrm{~g}$ at $20^{\circ} \mathrm{C}$ for $15 \mathrm{~min}$. The pellet then was resuspended in $1 \mathrm{ml}$ of Medium 199 (Gibco Laboratories) that contained $1.0 \%$ glutamine, $100 \mathrm{U} / \mathrm{ml}$ penicillin, and $100 \mu \mathrm{g} / \mathrm{ml}$ streptomycin (M199). The tachyzoites were counted in trypan blue, and the concentration was adjusted to 1.6 $\times 10^{7} / \mathrm{ml} .100-\mu \mathrm{l}$ aliquots were dispensed into individual tubes containing $100 \mu \mathrm{l}$ milk or IgA from either seropositive or seronegative control subjects and incubated at $37^{\circ} \mathrm{C}$ while rocking on a platform rocker (Bellco Biotechnology, Vineland, $\mathrm{NJ}$ ) at $10 \mathrm{rpm}$. Sera from uninfected and infected mice (23) were also incubated with tachyzoites as described above, as internal controls in each assay. After $30 \mathrm{~min}$, the volumes were adjusted to $400 \mu$ l with M199 containing 10\% FCS.

In vitro challenge. $100 \mu \mathrm{l}$ of enterocytes $\left(2 \times 10^{6} / \mathrm{ml}\right)$ were plated in each well of a microtiter plate (Flow Laboratories, Inc., McLean, VA) before challenge. After incubation for 1 to $3 \mathrm{~h}$ at $37^{\circ} \mathrm{C}, 5 \% \mathrm{CO}_{2}$, the monolayers were challenged with $100 \mu$ l of treated Me49 strain tachyzoites $\left(4 \times 10^{6} / \mathrm{ml}\right)$. After $1 \mathrm{~h}, 25 \mu \mathrm{l}\left[{ }^{3} \mathrm{H}\right]$ uracil $(50 \mathrm{Ci} / \mathrm{mmol}$, $100 \mu \mathrm{Ci} / \mathrm{ml}$; Amersham Corp., Arlington Heights, IL) was added to each well followed by incubation for $20 \mathrm{~h}$. Tachyzoites were harvested by alternating vigorous washing and aspirating with isotonic saline. They were collected on fiberglass filters with a multiple automated cell harvester (M.A. Bioproducts, Walkersville, MD [24]). Filters were dried and the tachyzoites were retained on each filter counted by liquid scintillation spectrophotometry to quantitate tachyzoite multiplication (23). Reduction in infection was expressed as the percent reduction of $\left[{ }^{3} \mathrm{H}\right]$ uracil incorporation compared with the seronegative whey control. To compare individual experiments, counts per minute of the 
negative control in separate experiments were normalized to 10,000 $\mathrm{cpm}$. This was done by assigning a value of 10,000 to control wells in which enterocytes were challenged with $T$. gondii pretreated with media and FCS only (i.e., untreated controls). Thus, normalized counts per minute were calculated as follows: $10,000 \times(\mathrm{cpm}$ treated [e.g., with whey]/cpm untreated control).

In addition, enterocytes were cultured and challenged in fourchamber slides (LabTek; Nunc, Naperville, IL) as previously described for macrophages (23), and numbers of enterocytes per field $(\times 400)$, percent infected cells, and mean number of tachyzoites per vacuole were assessed as previously described (23).

Thymidine uptake. To determine whether whey was toxic to the enterocytes and could result in fewer cells per culture well, $100 \mu \mathrm{l}$ of enterocytes that contained $2 \times 10^{5}$ enterocytes was plated in each well. Also, seven serial twofold dilutions of enterocytes were plated in triplicate to produce a standard curve for comparison. This was done because DNA and protein assays could not be used to quantitate enterocytes as the cultures were not washed before processing and, thus, measurement of DNA or protein would also reflect detached cells in the culture supernatant. After incubation for 1 to $3 \mathrm{~h}$ at $37^{\circ} \mathrm{C}, 5 \% \mathrm{CO}_{2}$, and $100 \%$ humidity, $100 \mu \mathrm{l}$ of diluted whey samples was added to the monolayers. After $1 \mathrm{~h}, 25 \mu \mathrm{l}\left[{ }^{3} \mathrm{H}\right]$ thymidine $(50 \mathrm{Ci} / \mathrm{mmol}, 50 \mu \mathrm{Ci} / \mathrm{ml}$; Amersham Corp.) was added to each well followed by incubation for $20 \mathrm{~h}$. Enterocytes were harvested by alternating vigorous washing and aspirating with isotonic saline. They were collected on fiberglass filters with a multiple automated cell harvester. Filters were dried and the DNA labeled with [ ${ }^{3} \mathrm{H}$ ] thymidine that was retained on each filter was counted by liquid scintillation spectrophotometry to estimate the number of enterocytes that were present and thus incorporating $\left[{ }^{3} \mathrm{H}\right]-$ thymidine.

Sabin Feldman dye test. This was performed as described (24).

Agglutination. This was performed using Formalin-fixed tachyzoites with the standardized direct agglutination test kit (Biomerieux, Marcy-L'Etoile, France) according to the manufacturer's instructions. Dilutions of whey and sera (dye test negative and positive for internal controls) were 1:40 and 1:4,000.

$S D S-P A G E$ and electrophoretic transfer. $\mathrm{RH}$ tachyzoites were obtained from tissue culture. They were dissolved in SDS gel sample buffer ( $1 \%$ 2-mercaptoethanol [Sigma Chemical Co.], $500 \mathrm{mM}$ Tris [Sigma Chemical Co.], $1 \%$ SDS, and $10 \%$ glycerol, pH 6.8). Approximately $2.5 \times 10^{7}$ tachyzoites ( $200 \mu \mathrm{g}$ protein) per lane were loaded onto a $12 \%$ Laemmli gel and subjected to electrophoresis at $30 \mathrm{~mA}$ for 4 to $5 \mathrm{~h}$ (25). The $T$. gondii antigens resolved by SDS-PAGE were transferred to a polyvinylidene difluoride membrane (Millipore Corp., Bedford, MA) using a semidry electroblotting apparatus (American Bionetics, Hayward, CA). The transfer buffer consisted of $25 \mathrm{mM}$ Tris, $40 \mathrm{mM} 6$-aminohexanoic acid, and $20 \%$ methanol, pH 9.4. A constant current of $2.5 \mathrm{~mA} / \mathrm{cm}^{2}$ was applied for $1 \mathrm{~h}$ at room temperature.

To determine whether antigens were polypeptides, lipids, or carbohydrates, $T$. gondii antigens were also treated with proteinase $\mathrm{K}$ (1 $\mathrm{U} / \mathrm{ml}$; Sigma Chemical Co.) for $1 \mathrm{~h}$, neuraminidase ( $1 \mathrm{U} / \mathrm{ml}$; Sigma Chemical Co.) for $4 \mathrm{~h}$, or periodate ( $10 \mathrm{nM}$, Sigma Chemical Co.) for $30 \mathrm{~min}$ and blotted as described (25).

Western blot. Polyvinylidene difluoride membranes were blocked overnight at $4^{\circ} \mathrm{C}$ with $5 \%$ non-fat powdered milk in buffer $(140 \mathrm{mM}$ $\mathrm{NaCl}, 0.05 \%$ Tween 20, in $15 \mathrm{mM}$ Tris, pH 8.0)(M-TNT). Strips were cut and incubated with whey sampl ss diluted 1:1 with M-TNT for $1 \mathrm{~h}$. After three washes with 5\% M-TNT, strips were incubated for $1 \mathrm{~h}$ with horseradish peroxidase-conjugated anti-human secretory component (Sigma Chemical Co.) diluted 1:1,000 in M-TNT. Blots were also probed with anti-human secretory IgA (Cappel Laboratories) and anti-human IgA (Sigma Chemical Co.). Sera from uninfected and infected mice (23) probed with goat antibody to mouse immunoglobulins (Cappel Laboratories) were also included in each assay as internal controls. Strips were washed three times in PBS and developed using a PBS substrate solution that contained $0.5 \mathrm{mg} / \mathrm{ml}$ diaminobenzidine (Sigma Chemical Co.), $0.2 \mathrm{mg} / \mathrm{ml} \mathrm{CoCl}_{2}$ (Sigma Chemical Co.), and $0.03 \% \mathrm{H}_{2} \mathrm{O}_{2}$ (Fisher Scientific, Fairlawn, NY) for $15 \mathrm{~min}$. An estima- tion of the molecular weight of the reactive polypeptides was determined using prestained molecular weight standards (Amersham Corp.) as a reference.

Statistics. Within each experiment there were triplicate cultures for each treatment group. Each experiment was repeated two or more times. Results are expressed as mean $\pm \mathrm{SD}$. To permit comparisons between experiments, counts per minute in individual experiments were normalized to $10,000 \mathrm{cpm}$ (i.e., [cpm treated/cpm untreated] $\times 10,000)$. Effects of treatment of tachyzoites in the enterocyte challenge were analyzed using the Neuman-Keuls multiple-range test. Correlation coefficients were determined by regression analysis. Differences were considered significant when $P<0.05$.

\section{Results}

Secretory IgA ELISA. Whey from three of three acutely infected mothers contained $T$. gondii-specific secretory IgA when tested in ELISAs (Fig. 1). ELISA values with whey from the chronically infected and seronegative women were substantially less (Fig. 1). There was no definitive association between concentrations of total IgA and presence of $T$. gondii-specific secretory IgA demonstrated by ELISA (Fig. 1). Specifically, data in Fig. 1 indicate that two women had whey with higher amounts of total IgA and specific antibody to $T$. gondii and two women had whey with higher amounts of total IgA and no specific antibody to $T$. gondii. Two of four samples with substantial total IgA had substantial specific IgA antibody to $T$.
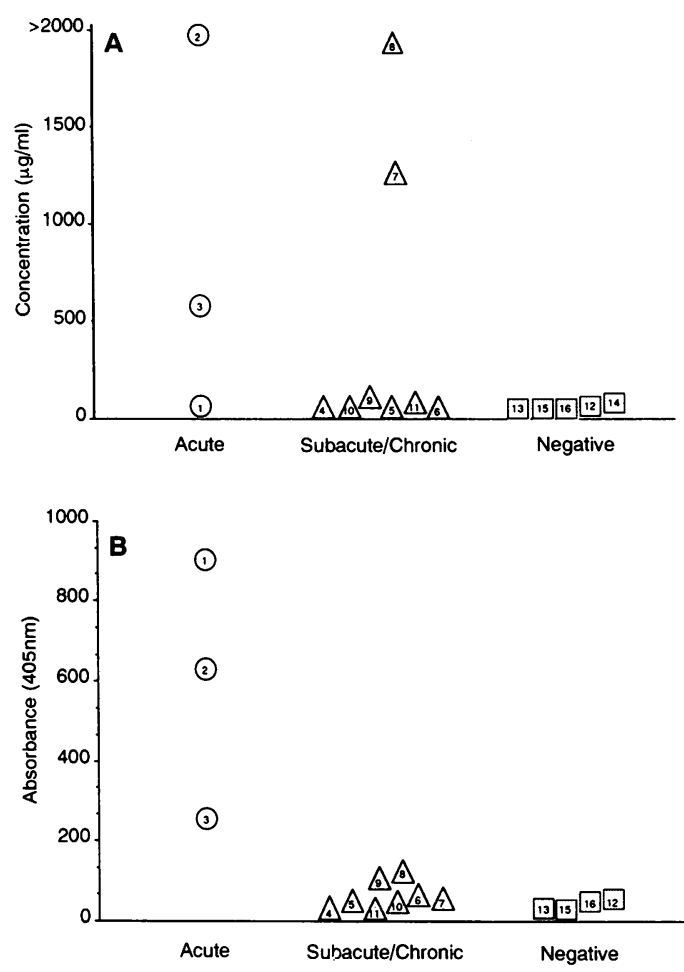

Figure 1. Whey from $T$. gondii-infected humans contains secretory IgA specific for $T$. gondii demonstrated by using an ELISA. $(A)$ Amount of total IgA. Note this does not correlate with amount of specific secretory $\operatorname{IgA}$ in $B$. (B) $T$. gondii-specific secretory IgA. Each number inside a symbol represents a subject. These numbers are the same as those used in all other Figures and Tables. The lower limit of detection in $A$ was $0.145 \mu \mathrm{g} / \mathrm{ml}$ and the control absorbances in $B$ were 42-111 absorbance units. Whey from one negative control (subject 14) had higher absorbances in some experiments, which reflected nonspecific reactivity (data not shown). 


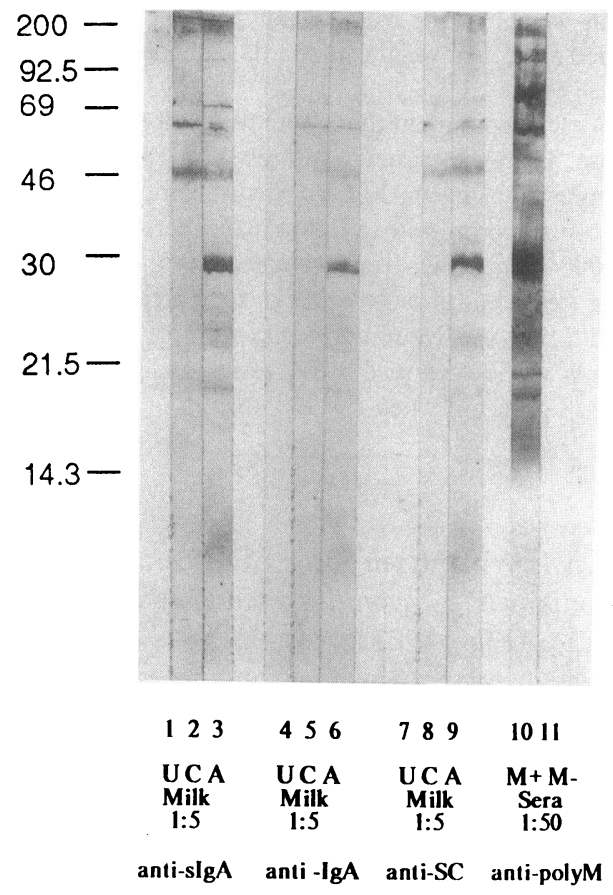

Figure 2. Western blots that indicate molecular masses of antigens of $T$. gondii recognized by human whey. $U$, whey from initially studied uninfected woman (subject 16 ); $C$, whey from initially studied chronically infected woman (subject 5); $A$, whey from initially studied acutely infected woman (subject 3 ). Antigens are those recognized when probed with antibody to secretory $\operatorname{IgA}($ anti-SlgA), IgA (anti-IgA), and secretory piece (anti-SC). Sera from infected $(M+)$ and uninfected mice $(M-)$ controls were probed with antibody to mouse immunoglobulin (anti-poly $M$ ). Note 30- and 46- kD bands in whey from subject 3 and very faint $46-\mathrm{kD}$ band in whey from subject 5 . gondii, and 1 of 12 samples without substantial total $\operatorname{IgA}$ had substantial specific IgA antibody to $T$. gondii.

Western blots. Epitopes recognized by this secretory IgA were defined by Western blot (Figs. 2 and 3 and summarized in Table II). Whey was demonstrated to contain some complete secretory IgA for the first patients identified, as it was detected when antibody to secretory piece and IgA were used as well as antibody to human secretory IgA (Fig. 2). Treatment of nitrocellulose strips of electrophoresed Toxoplasma antigens with periodate $(10 \mathrm{nM})$ for $30 \mathrm{~min}$, neuraminidase $(1 \mathrm{U} / \mathrm{ml})$ for 4 $\mathrm{h}$, or protease (proteinase $\mathrm{K})(1 \mathrm{U} / \mathrm{ml})$ for $1 \mathrm{~h}$ demonstrated that all these antibodies were directed against proteins.

Enterocyte challenge. An in vitro enterocyte challenge assay was developed to determine whether these antibodies had potential biological significance in protection against $T$. gondii. Me49 strain tachyzoites were incubated with whey, and in subsequent experiments with jacalin-purified secretory IgA subclass 1 . Whey from the initially studied acutely infected mother, and to a lesser extent whey from the initially studied chronically infected mother, inhibited replication after in vitro T. gondii challenge in a dose-dependent manner(Fig. 4). Replication was measured as tritiated uracil uptake (Fig. 4). These results were confirmed when whey from all 16 women were studied simultaneously (Fig. $5 A$ and $B$ ). Results were the same whether data are expressed as normalized data from replicate experiments (Fig. $5 \mathrm{~A}$ ) or counts per minute for a single representative experiment (Fig. $5 \mathrm{~B}$ ).

IgA 1 was purified using a jacalin affinity column. This IgA 1 from the acutely infected mother, but not the seronegative mother, also inhibited $T$. gondii. Data from a representative experiment are in Fig. 6.

Whey was not toxic to the enterocytes. There was no difference in thymidine uptake of enterocytes treated with media,

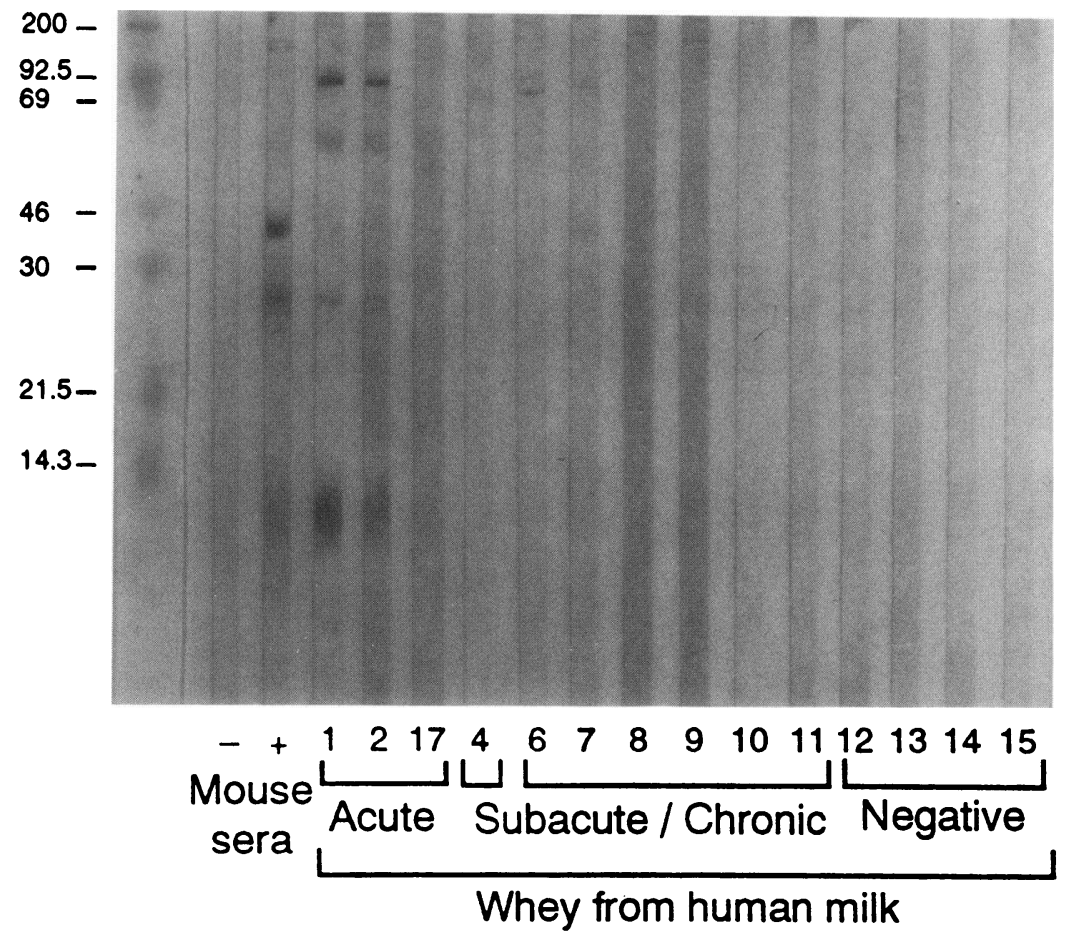

Figure 3. Western blots with whey from the other 14 women. There was a very faint band at $30 \mathrm{kD}$ for subject 17 , which is not seen in this photograph. There is a $30-\mathrm{kD}$ doublet in subject 2's whey. Also note the 46-kD bands in whey from subjects $1,2,3$, 17, and 7. A faint band at $46 \mathrm{kD}$ was seen on the original blots for subject 6 but is not clearly seen in this photograph. 
Table II. Correlation of Presence of T. gondii-specific Secretory IgA in ELISA, Epitopes Recognized in Western Blots, and Inhibitory Effect of Whey on Subsequent Replication of T. gondii in Enterocytes

\begin{tabular}{|c|c|c|c|c|c|c|c|c|c|c|c|c|c|c|c|c|c|}
\hline \multirow{2}{*}{$\begin{array}{l}\text { Molecular } \\
\text { mass of } \\
\text { epitope }\end{array}$} & \multicolumn{4}{|c|}{ Acute } & \multicolumn{9}{|c|}{ Subacute/chronic } & \multicolumn{4}{|c|}{ Uninfected } \\
\hline & $1^{*}$ & 2 & $3^{\ddagger}$ & 17 & $4^{\S}$ & 5 & 6 & 7 & 8 & 9 & 10 & 11 & 12 & 13 & 14 & 15 & 16 \\
\hline \multicolumn{18}{|l|}{$k D$} \\
\hline$>100$ & + & + & + & & & & \pm & + & + & + & & & & & & & \\
\hline $69-92$ & ++ & ++ & + & & + & & + & + & & & & & & & & & \\
\hline $46-69$ & + & + & + & + & & + & & & & & & & & & & & \\
\hline 46 & + & + & + & + & & + & + & + & & & & & & & & & \\
\hline 30 & ++ & ++ & ++ & \pm & & & & & & & & & & & & & \\
\hline $21-30$ & & & ++ & & & & & & & & & & & & & & \\
\hline 22 & \pm & \pm & + & & & & & & & & & & & & & & \\
\hline$\leq 14$ & + & + & + & & & & & & & & & & & & & & \\
\hline \multicolumn{18}{|l|}{ T. gondii-specific } \\
\hline ELISA results (OD) & 917 & 642 & 266 & ND & 25 & 64 & 78 & 69 & 134 & 115 & 61 & 1 & 111 & 42 & -1 & 65 & 58 \\
\hline Percent inhibition" & $>75$ & 50 & 50 & ND & 0 & 50 & 40 & 40 & 15 & 15 & 0 & 0 & 0 & 0 & 0 & 0 & 0 \\
\hline
\end{tabular}

++ , strongly positive; + , present; \pm , equivocal. * Subject number. ${ }^{\ddagger}$ This whey sample also contained secretory IgA that recognized epitopes between 14 and $22 \mathrm{kD}$. $\$$ Treated with Spiramycin during gestation. "Whey from this seronegative mother had nonspecific reactivity in some assays. "Percent inhibition, percent inhibition of $T$. gondii infection of enterocytes due to whey. Inhibition appeared to correlate with presence of $T$. gondii secretory IgA to epitopes $\leq 46 \mathrm{kD}$ demonstrated in Western blots.

whey from the seronegative mother, or whey from the acutely infected mother. This assay detected less than twofold differences in enterocyte numbers accurately. Numbers of cells per high-power field evaluated by light microscopy were not altered by incubation with the whey sample.

Microscopic analysis revealed that whey diminished infection of enterocytes by $T$. gondii but not subsequent replication of $T$. gondii. Specifically, in a representative experiment, in

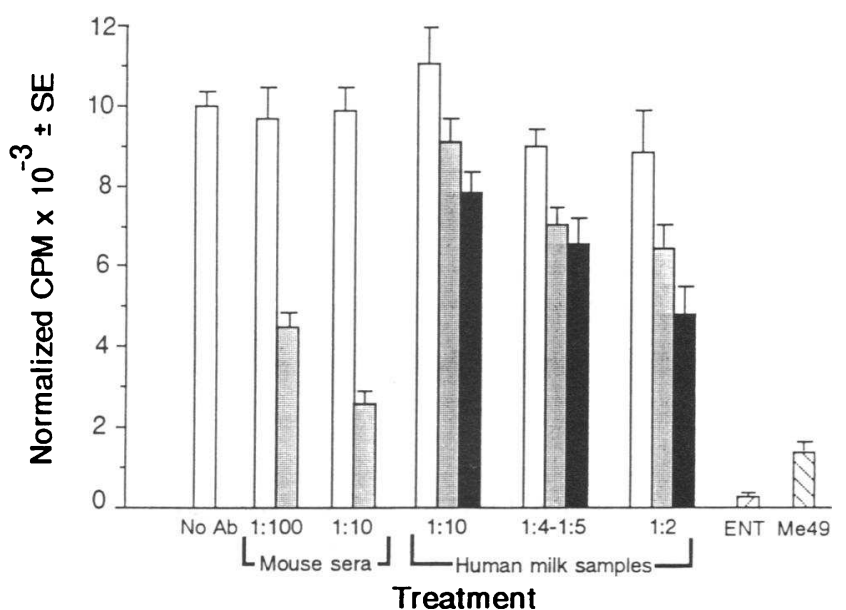

Figure 4. Effect of incubation of Me49 strain T. gondii tachyzoites with whey on their subsequent replication in enterocytes in vitro. $\square$, No Ab, refers to effect of media alone; $\square$, effect of sera from seronegative mice or whey from a seronegative human mother; $\square$, effect of sera from chronically infected mice or milk from the chronically infected mother; and $\mathbf{a}$, effect of whey from the acutely infected mother. Differences between milk from uninfected and infected individuals were significant. $E N T$ refers to counts per minute from enterocytes in culture alone; Me49 refers to counts per minute from the Me49 strain of $T$. gondii in culture alone. cultures challenged with $T$. gondii treated with whey from an acutely infected mother versus those treated with whey from an uninfected mother, there were 21 versus $40 \%$ infected enterocytes at $1 \mathrm{~h}$ after challenge and 26 versus $62 \%$ infected enterocytes at $18 \mathrm{~h}$ after challenge. Whey did not alter the mean number of tachyzoites per vacuole ( $\geq 4$ vs. $\geq 4$ ).

Sabin Feldman dye test. Human whey did not result in complement-dependent lysis of $T$. gondii.

Direct agglutination. Whey and jacalin affinity-purified secretory IgA from the two most recently infected mothers (subjects 1 and 2) agglutinated $T$. gondii tachyzoites. Whey from the other acutely infected mother (subject 3 ), who also was untreated, did not agglutinate $T$. gondii tachyzoites. This suggests that one mechanism of action of secretory $\operatorname{IgA}$, but not the only one, could be agglutination of $T$. gondii.

\section{Discussion}

In earlier studies, we demonstrated that mice have intestinal IgA specific for $T$. gondii (26). Whey from uninfected, chronically, and acutely infected mothers was studied to determine whether humans also have $T$. gondii-specific secretory $\operatorname{IgA}$ and to obtain larger quantities of antibodies to facilitate characterization of such secretory IgA. The present studies demonstrate that $T$. gondii-infected humans produce secretory IgA specific to $T$. gondii. These antibodies recognize $T$. gondii proteins of $\sim 14,22,26-28,30-35,46,60,70-80$ and $>100 \mathrm{kD}$. Although SAG1 (p30) appeared to be the major epitope identified by whey from acutely infected versus chronically infected women, there was not an absolute correlation between inhibitory activity on $T$. gondii replication within enterocytes and presence of secretory antibody to SAG1 (Table II).

To simulate the natural route of infection, i.e., oral ingestion of $T$. gondii followed by subsequent invasion of the intestinal mucosa, an enterocyte challenge assay was developed. 


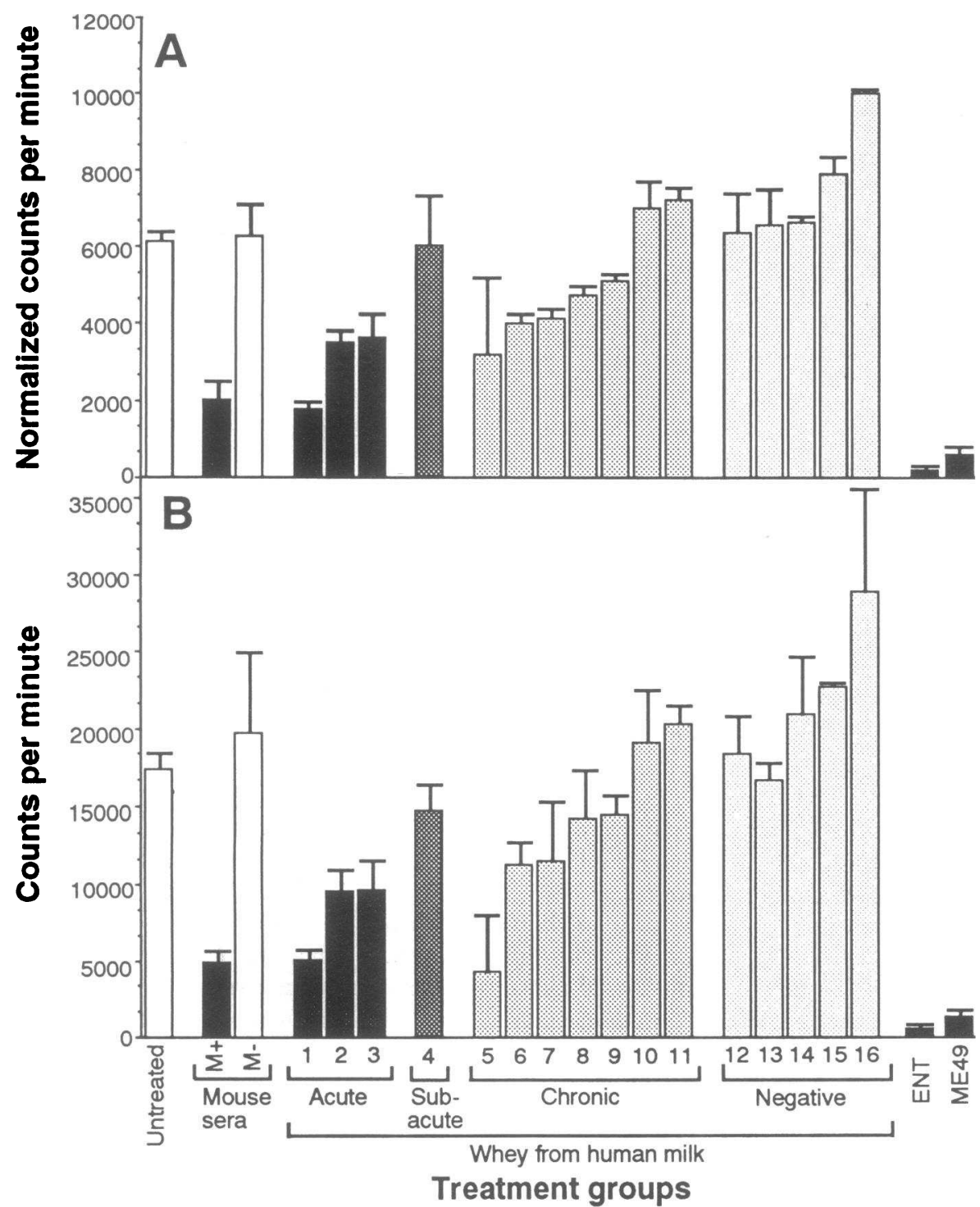

Figure 5. Effect of treatment (incubation) of tachyzoites with whey from 16 women on Me49 strain $T$. gondii infection of enterocytes in vitro. $(A)$ Normalized data pooled from at least two representative experiments. $(B)$ Representative experiments $(\mathrm{cpm})$. Numbers are the same as used in other Tables and Figures to indicate whey from individual subjects. Differences between whey from uninfected and infected individuals were significant. $\square$, Untreated, refers to enterocytes challenged with Toxoplasma treated and cultured with media alone. $M+$, treatment with sera from infected mice; $\square M-$, sera from uninfected mice; $\mathbf{n}$, treatment with whey from acutely infected woman; $\mathbf{m}$, treatment with whey from subacutely infected woman; $:$, treatment with whey from chronically infected woman; $\square$, treatment with whey from uninfected woman. ENT refers to counts per minute from enterocytes in culture alone; Me49 refers to counts per minute from the Me49 strain of $T$. gondii in culture alone.

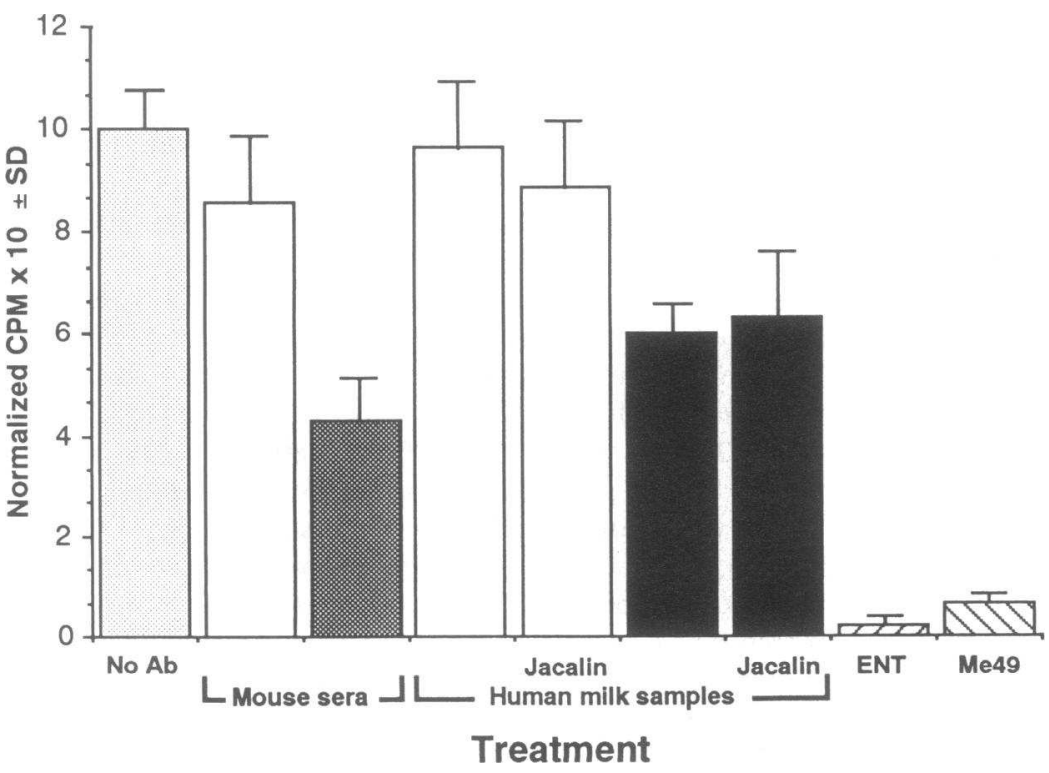

Figure 6. Effect of milk, secretory IgA isolated from whey using a jacalin-affinity column, and mouse sera on the subsequent replication of Me49 strain $T$. gondii tachyzoites in enterocytes challenged in vitro. $\square$, Effect of media alone; $\square$, effect of sera from the seronegative mice or human whey or secretory IgA isolated from this whey (whey, jacalin) from the seronegative mother; $\mathbf{m}$, effect of serum from the chronically infected mouse, and $\mathrm{m}$, effect of whey, or secretory IgA isolated from this milk (whey, jacalin), from the acutely infected woman. Dilutions of mouse sera were $1: 10$ and whey were $1: 2$. The sera from the infected mouse and milk and IgA from the infected individual significantly reduced counts per minute. 
The Me49 strain of $T$. gondii was adapted from its murine host to a tissue culture propagation system. The now rapidly dividing tachyzoites were used to infect rat enterocytes (22) in vitro. Quantitation of infection was assessed by incorporation of $\left[{ }^{3} \mathrm{H}\right]$ uracil into multiplying tachyzoites (23). Enterocytes lack the salvage enzyme, uracil phosphoribosyltransferase, so that $\left[{ }^{3} \mathrm{H}\right]$ uracil incorporation is confined to the parasite. Although possibly introducing a degree of artificiality to the assay, we selected a nonmalignant rat small intestinal cell line. At the time of these studies, the only human intestinal cell line available was a malignant colonic line. A nonmalignant, well-differentiated human small intestinal cell line has now been propagated. With the rat enterocyte assay system, we found that incubation of tachyzoites with either human whey or purified secretory IgA 1 subtype from this whey (of the acutely, some of the chronically, but not of the uninfected mother[s]) reduced subsequent intracellular replication of $T$. gondii. It will be of interest to determine whether human secretory IgA also blocks uptake into human cells.

Secretory IgA may protect mucosal surfaces by prevention of attachment to or colonization of mucosal surfaces and entry into susceptible cells. In other systems, (e.g., as demonstrated for reo and influenza viruses) (8-10), but not studied in our experiments, this is by sterically blocking the association of an organism with cellular receptors. Our experiments indicate that $T$. gondii-specific IgA in whey does not inhibit invasion by $T$. gondii through complement-dependent lysis. This is consistent with the known low efficiency of IgA for complement-dependent lysis. Two of three inhibitory whey samples agglutinated tachyzoites. Thus, agglutination could be one mechanism of inhibition, but not the only one. In separate studies (26a, Mineo, J. R., D. Mack, I. Kahn, K. Ely, J. Smith, R. McLeod, and L. Kasper, manuscript submitted for publication), we and others have demonstrated that polyclonal, monospecific, and monoclonal antibodies to SAG1 (p30) inhibit infection within enterocytes, fibroblasts, and MDBK cells (Mineo, J. R., D. Mack, I. Kahn, K. Ely, J. Smith, R. McLeod, and L. Kasper, manuscript submitted for publication ). Also, Fabs of the polyclonal, monospecific antibody to SAG 1 block infection of fibroblasts by wild-type $T$. gondii tachyzoites that have surface SAG1 but not by mutant tachyzoites that do not have SAG1 (Mineo, J. R., D. Mack, I. Kahn, K. Ely, J. Smith, R. McLeod, and L. Kasper, manuscript submitted for publication). These studies also demonstrate that SAG1 participates in $T$. gondii's invasiveness through interaction with a host cell glycosylated molecules (Mineo, J. R., D. Mack, I. Kahn, K. Ely, J. Smith, R. McLeod, and L. Kasper, manuscript submitted for publication ). Antibody to the major $30-\mathrm{kD}$ epitope (SAG1) is present in three of three inhibitory whey samples from acutely infected mothers (demonstrated in Figs. 2 and 3, summarized in Table II). Dot blot with affinity-purified SAG1 confirmed that this antibody in whey was to SAG1 (our unpublished data). Thus, agglutination is one mechanism whereby subsequent replication of $T$. gondii could be inhibited. Other mechanisms also are operative because the Fab portion of antibody to p30 blocks infection of host cells, a host cell receptor for SAG1 has been partially characterized (Mineo, J. R., D. Mack, I. Kahn, K. Ely, J. Smith, R. McLeod, and L. Kasper, manuscript submitted for publication), and we have demonstrated that antibody in human whey recognizes this epitope.

For studies of the initial samples (Fig. 2), antisera to secre- tory $\operatorname{IgA}, \operatorname{IgA}$, and secretory piece were used to demonstrate that intact secretory IgA was reactive rather than just IgA monomers. Antibodies to IgA1 and IgA2 were not further differentiated by Western blotting. As jacalin isolates only subtype IgA1, there may be other substances in whey (e.g., IgA2 or IgG) from infected women that contribute to differences in uracil incorporation.

As we have found that human whey contains a $T$. gondiispecific secretory $\operatorname{IgA}$ antibody that can reduce infection in enterocytes in vitro, it may be possible to stimulate such an antibody in vivo. This could then contribute to protection against peroral acquisition of $T$. gondii. There are a number of other examples of pathogen-specific $\operatorname{IgA}$ in milk $(17,18)$ and protection provided by sIgA or milk that presumably contains such IgA $(3-7,16,18)$, as well as protection against certain pathogens (e.g., polio virus) conferred by oral immunization. The studies described herein, as well as work with other microorganisms $(3-7,16-18)$, provide a rationale for future studies to determine whether such $T$. gondii-specific IgA antibody also protects in vivo. They provide a basis to further characterize the $T$. gondii epitope(s) that stimulate(s) such protective antibody and to determine whether intestinal immunization (27) can protect against acquisition of $T$. gondii.

\section{Acknowledgments}

We gratefully acknowledge Dr. Jack Remington's laboratory for performing the serologic studies, the women who donated milk for this study, and the assistance of Ms. D. Patton and E. Holfel in preparation of the manuscript.

This work was supported by National Institutes of Health grant AI-16945-09.

\section{References}

1. McLeod, R., and J. S. Remington. 1992. Toxoplasmosis. In Nelson's Textbook of Pediatrics, 14th ed. R. L. Behrman, R. M. Kliegman, V. C. Vaughan III, and W. E. Nelson, editors. W. B. Saunders Company, Philadelphia. 883-892.

2. McLeod, R., and J. S. Remington. 1992. Toxoplasmosis. In Infectious Diseases in Medicine and Surgery. J. Bartlett, S. Gorbach, N. Blacklow, editors. W. B. Saunders Company, Philadelphia. 1328-1343.

3. Appleton, J. A., and D. D. McGregor. 1984. Rapid expulsion of Trichinella spiralis in suckling rats. Science (Wash. DC). 226:70.

4. Mietens, C., H. Keinhurst, H. Hilpert, H. Gerber, H. Amster, and J. J. Dahud. 1979. Treatment of infantile $E$. coli gastroenteritis with specific bovine anti-E. coli milk immunoglobulins. Eur. J. Pediatr. 132:239-252.

5. Hilpert, H., H. Brussow, C. Mietens, J. Sidoti, L. Lerner, and H. Werchau. 1987. Use of bovine milk concentrate containing antibody to rotavirus to treat rotavirus gastroenteritis in infants. $J$. Infect. Dis. 156:158-166.

6. Tzipori, S., D. Robertson, and C. Chapman. 1987. Remission of diarrhea due to cryptosporidiosis in an immunodeficient child treated with hyperimmune bovine colostrum. Br. Med. J. 293:1276-1277.

7. Glass, R. I., A. M. Svennerholm, and B. J. Stoll. 1983. Protection against cholera in breast-fed children by antibodies in breast milk. N. Engl. J. Med. 308:1389-1392.

8. Levine, M. D., D. R. Nalin, D. L. Hoover, E. J. Bergquist, R. B. Nornick, and C. R. Young. 1979. Immunity to enterotoxigenic Escherichia coli. Infect. Immun. 23:729-726.

9. Lee, P. W. K., E. C. Hayes, and W. K. Joklik. 1981. Protein SIGMA 1 is the reovirus attachment protein. Virology. 108:156-163.

10. Taylor, H. P., and N. J. Dimmock. 1985. Mechanisms of neutralization of influenza virus by secretory $\operatorname{IgA}$ is different from that of monomeric $\mathrm{IgA}$ or $\mathrm{IgG}$. J. Exp. Med. 11:198-209.

11. Ogra, P. L. 1984. Mucosal immune response to poliovirus vaccines in childhood. Rev. Infect. Dis. 6:S361-S368.

12. Gregary, R. L., and S. J. Filler. 1987. Protective secretory immunoglobulin A antibodies in humans following oral immunization with Streptococcus mutans. Infect. Immun. 55:2409-2415.

13. Clancy, R. L., A. W., Cripps, A. J. Husband, and D. Buckley. 1983. Specific immune response in the respiratory tract after administration of an oral polyvalent bacterial vaccine. Infect. Immun. 39:491-496. 
14. Tagliabue, A., L. Villa, M. T. Magistris, M. Romano, S. Silvestri, D. Boraschi, and L. Nencioni. 1986. IgA-driven T cell-mediated antibacterial immunity in man after live oral Ty 21 a vaccine. J. Immunol. 137:1504-1510.

15. Davis, P. J., and P. Porter. 1983. Eimeria: control of parasitic behavior through mucosal immunity and in-feed immunization. The secretory immune system. Vol. 409. J. R. McGhee, and J. Mestecky, editors. The New York Academy of Sciences, New York. 810-811.

16. Lloyd, S., and E. J. L. Soulsby. 1978. The role of IgA immunoglobulins in the passive transfer of protection to Taenia taeniaeformis in the mouse. Immunology. 34:939-945.

17. Nayak, N., N. K. Ganguly, B. N. Walis, and V. Wahi. 1987. Specific secretory IgA in the milk of Giardia lamblia-infected and uninfected women. $J$. Infect. Dis. 155:724-727.

18. Fayer, R., L. E. Perreyman, and M. W. Riggs. 1989. Hyperimmune bovine colostrum neutralizes Cryptosporidium sporozoites and protects mice against oocyst challenge. J. Parasitol. 75:151-153.

19. Waldman, R. H., J. Stone, V. Lazzell, K. C. Bergmann, R. Khakoo, A Jacknowitz, S. Howard, and C. Rose. 1983. Oral route as method for immunizing against mucosal pathogens. The secretory immune system. Vol. 409. J. R. McGhee, and J. Mestecky, editors. The New York Academy of Sciences, New York. 510-516.
20. Lowry, O. H., N. J. Rosebrough, A. L. Farr, and R. J. Randall. 1951. Protein measurement with the folin phenol reagent. J. Biol. Chem. 193:255.

21. Rogue-Barreira, M. C., and A. Campos-Neto. 1985. Jacalin: an IgA-binding lectin. J. Immunol. 134:1740-1743.

22. Quaroni, A., J. Wands, R. L. Trelstad, and K. J. Isselbacher. 1979. Epithelioid cell cultures from rat small intestine. J. Cell Biol. 80:248-265.

23. McLeod, R., R. G. Estes, D. G. Mack and H. Cohen. 1984. Immune response of mice to ingested Toxoplasma gondii: a model of Toxoplasma infection acquired by ingestion. J. Infect. Dis. 149:234-244.

24. Frenkel, J. K., and L. Jacobs. 1956. Ocular toxoplasmosis. Arch. Ophthalmol. 59:260-279.

25. Laemmli, U. K. 1970. Cleavage of structural proteins during the assembly of the head of bacteriophage T4. Nature (Lond.). 227:680-685.

26. McLeod, R., and D. Mack. 1986. Secretory IgA specific for Toxoplasma gondii. J. Immunol. 136:2640-2643.

26a.Grimwood, J., and J. E. Smith. 1992. Toxiplasma gondii: role of a 30 kDa surface protein in invasion. Exp. Parasitol. 74:106-111.

27. McLeod, R., J. K. Frenkel, R. G. Estes, D. G. Mack, P. B. Eisenhauer, and G. Gibori. 1988. Subcutaneous and intestinal vaccination with tachyzoites of Toxoplasma gondii and acquisition of immunity to peroral and congenital toxoplasma challenge. J. Immunol. 140:2632-2637. 